\title{
NUEVAS TECNOLOGÍAS, UNIVERSIDAD Y EDUCACIÓN ARTÍSTICA: EL DISEÑO DE WEBQUESTS CON RÚBRICAS DE EVALUACIÓN EN LA FORMACIÓN DE FORMADORES
}

\author{
NEW TECHNOLOGIES, UNIVERSITY AND ART EDUCATION: \\ WEBQUESTS DESIGN WITH RUBRICS OF EVALUATION IN THE \\ TRAINING OF TRAINERS
}

\author{
Pedro V. Salido \\ pedrov.salopez@gmail.com \\ Universidad de Castilla-La Mancha
}

\section{RESUMEN}

Tras la entrada en vigor del Espacio Europeo de Educación Superior (EEES), se reforzó la idea de un nuevo concepto de educación relacionado con las posibilidades didácticas de las Nuevas Tecnologías. En este contexto formativo, han sido numerosas las herramientas 2.0 que han pasado a formar parte de los recursos puestos a disposición de docentes y alumnos. Es por ello que la Universidad debe formar a los futuros profesionales de la educación para que sean capaces de utilizar correctamente las tecnologías en las aulas. En este sentido, el artículo que presento a continuación resume la segunda fase de un proyecto de investigación-acción sobre el diseño de WebQuests con rúbricas de evaluación llevado a cabo en el Grado de Maestro en Educación Primaria (UCLM) de manera paralela a los contenidos de Educación Artística incluidos en el plan de estudios.

PALABRAS CLAVE: WebQuest, Educación Artística, Web 2.0, rúbrica, Educación Superior.

\section{ABSTRACT}

With the entry into force of the European Space of Higher Education (ESHE), a new concept of education related to the didactic possibilities of the new technologies was put into practice. In this educational context, the 2.0 tools have become part of the available resources to teachers and students. For this reason, the University must train 
future professionals of education to be able to use properly the new technologies in Education. In this article I present some conclusions about an experience to design WebQuests with rubrics of evaluation. This experience was developed in the area of Art Education with future teachers of Primary Education (UCLM).

KEYWORDS: WebQuest, Art Education, Web 2.0, rubric, Higher Education.

\section{INTRODUCCIÓN}

En 1995, Bernie Dodge desarrolló junto a Tom March el modelo WebQuest. Su planteamiento, llevado a cabo en la Universidad Estatal de San Diego, se basó en una publicación en la World Wide Web que pretendía ser una guía de aprendizaje y de investigación fundamentada en gran parte o en su totalidad en información accesible a través de Internet (Dodge, 1995).

A día de hoy, una simple búsqueda en la Red sobre esta herramienta didáctica demuestra que veinte años después la propuesta de Dodge y March sigue gozando de una enorme vitalidad en las aulas. La WebQuest ha experimentado un notable avance en Educación, sobre todo tras el desarrollo del concepto Web 2.0 y del cambio en los modelos de formación manifestado con elementos curriculares como la conocida competencia digital.

Si bien, no todas las propuestas accesibles con un simple "click" y que responden a la estructura de la WebQuest deberían incluirse bajo este concepto. Ante esta situación, surge la necesidad de generar herramientas que sirvan de guía para el diseño de recursos 2.0 ajustados a las exigencias pedagógicas y didácticas de cada disciplina y etapa de la educación.

Con este objetivo en el horizonte, se planteó en el área de Educación Artística de la Facultad de Educación de Ciudad Real (UCLM) un proyecto de investigación-acción que permitiera, además de establecer junto a los futuros profesionales de la educación las líneas de actuación para un uso adecuado de la WebQuest en el aula, generar una rúbrica de evaluación válida para ajustar el diseño de estas guías didácticas a unos mínimos de calidad.

Esta primera fase de intervención en el aula, vinculada a la Educación Superior, permitió el desarrollo de algunos proyectos más. En uno de ellos, al que dedicaremos las páginas siguientes, se planteó el diseño de WebQuests con rúbricas de evaluación destinadas al alumnado de Educación Primaria. El objetivo primordial de esta experiencia de aula fue que un grupo de investigación ajeno al que intervino en la primera fase de investigación valorara de manera crítica si la rúbrica de evaluación facilitada era accesible y de fácil interpretación para aquellos que se enfrentaban a su lectura por primera vez. Asimismo, se volvieron a plantear líneas de actuación para fomentar entre el colectivo de profesionales de la educación el uso de esta herramienta en el diseño de procesos de enseñanza-aprendizaje con carácter construccionista. 


\section{El diseño de WebQuest con rúbricas de evaluación en la formación de formadores: el caso del área de Educación Artística}

\subsection{La intervención en el aula: investigación-acción en educación}

Desde que Kurt Lewin definiera la investigación-acción como forma de indagación en la década de los cuarenta del siglo $\mathrm{XX}$, han sido numerosos los estudiosos que se han preocupado por establecer las principales características de un método propio de las ciencias humanas y sociales. En educación cobró protagonismo con los trabajos de Wilfred Carr y Stephen Kemmis (1988), los de John Elliott (1990/2010) o los de Pamela Lomax (1995), que intentaron definir una metodología de intervención en la que el profesional hace uso en su práctica de la función investigadora para intentar mejorar la calidad de la enseñanza.

Es por todo ello que este método de indagación en el aula permite mejorar la práctica educativa en su escenario habitual. Además, aúna en un mismo proceso investigaciónacción-formación y hace protagonista del proceso de innovación educativa a la mayor parte de la comunidad educativa.

Con las técnicas de observación y recogida de datos propias de este enfoque metodológico (Latorre, 2008, 53), la experiencia de aula que se ha planteado en torno al concepto "WebQuest" se ha organizado atendiendo a las siguientes fases:

1. Primera fase: en este primer momento de intervención, desarrollado en el aula de Educación Plástica y Visual con los alumnos y alumnas del Grado de Maestro en Educación Primaria, se trabajó para dar a conocer unas líneas de alfabetización para el manejo de las Nuevas Tecnologías en el aula $y$, de manera concreta, para el uso de la WebQuest como herramienta didáctica construccionista. Asimismo, se planteó el diseño de una rúbrica de evaluación de WebQuests válida para su uso en cualquier nivel educativo (Salido, 2014).

2. Segunda fase: en este segundo momento de la experiencia, al que dedicaremos el resto de este trabajo, se planteó el diseño de nuevas WebQuests con un grupo de alumnos y alumnas de la misma asignatura -Educación Plástica y Visual-, pero independiente del de la primera fase. La referencia fundamental para el trabajo fue la rúbrica de evaluación diseñada en la fase anterior.

3. Tercera fase: está previsto que la experiencia continúe con el alumnado del Curso de Adaptación al Grado de Maestro en Educación Primaria. En este momento también se trabajará en el área de Educación Artística, pero el grupo de investigación será diferente. El alumnado de este curso se corresponde con antiguos diplomados en Magisterio que ahora adaptan su titulación a los estudios de Grado. En este caso, encontramos un elevado porcentaje de miembros mayores de 35 años, peculiaridad que nos permitirá comprobar la cuestionada distinción entre "nativos digitales" e "inmigrantes digitales" hecha por Marc Prensky (2001, 1-6) a través de la aplicación de Internet a la Educación. 


\subsection{El concepto de WebQuest como base de la investigación}

Como es evidente, la base de la investigación planteada en este contexto de Educación Superior pasa por el análisis del concepto de WebQuest como método de aprendizaje en la Sociedad del Conocimiento. En este sentido, partimos de las aportaciones de su creador, que presentó la WebQuest como una herramienta de investigación basada en información que proviene total o parcialmente de la Web:

A WebQuest is an inquiry-oriented activity in which some or all of the information that learners interact with comes from resources on the internet, optionally supplemented with videoconferencing (Dodge, 1995).

Si bien, y atendiendo a las aportaciones de Jordi Adell, bajo este concepto no se deben incluir las tareas de repetición y copia de la información ofrecida de manera virtual:

[...] una WebQuest es una actividad didáctica que propone una tarea factible y atractiva para los estudiantes y un proceso para realizarla durante el cual, los alumnos harán cosas con información: analizar, sintetizar, comprender, transformar, crear, juzgar y valorar, crear nueva información, publicar, compartir, etc. La tarea debe ser algo más que simplemente contestar preguntas concretas sobre hechos o conceptos (como en una Caza del Tesoro) o copiar lo que aparece en la pantalla del ordenador a una ficha [...] (Adell, 2004).

Como es bien sabido, esta tarea de investigación a realizar por los destinatarios de la WebQuest se lleva a cabo a través de una estructura más o menos fija que, atendiendo al concepto de "andamio de aprendizaje" (Adell, 2004), incluye los siguientes apartados:

- Introducción: debe ser motivadora y sirve para presentar al usuario el problema expuesto en los pasos siguientes y cómo se va a resolver.

- Objetivos: dan a conocer las capacidades a alcanzar con la realización de la WebQuest; en ocasiones pueden aparecer formulados al final de la introducción.

- Tarea: permite al usuario sintetizar, organizar, clasificar y transformar en conocimiento la información recogida de Internet y en diferentes publicaciones científicas sobre el tema a estudiar. Es el medio para conseguir los objetivos propuestos y puede estar diseñada atendiendo a características que van desde la recopilación crítica de información textual o visual a la creación de productos artísticos.

- Proceso: da a conocer de una manera muy estructurada y clara los pasos para resolver la tarea y el resultado final (desde una presentación Power Point, un mapa conceptual, una creación artístico-plástica o audiovisual a una obra de Net.Art).

- Recursos: presenta referencias a recursos on-line y material impreso de interés para poder llevar a cabo un proceso de aprendizaje construccionista y ampliar los conocimientos (publicaciones on-line, recursos de biblioteca, imágenes, vídeos, mapas conceptuales o cualquier otro material de interés) 
- Evaluación: presenta los criterios cualitativos y cuantitativos para que el usuario conozca qué se va a evaluar y cómo. Para este fin se suelen utilizar rúbricas que, además de implicar al estudiante en su proceso de evaluación, hacen el proceso de valoración mucho más objetivo (Roig Vila, 2014, 406).

- Conclusión: permite dar a conocer los principales logros conseguidos, invitando a la reflexión sobre el tema investigado.

La mayor parte de las plataformas para la publicación de WebQuests permiten, además, añadir una imagen descriptiva de cada uno de los apartados. Dado el potencial pedagógico y didáctico de la imagen, y sobre todo teniendo en cuenta que estamos planteando un proyecto para el área de Educación Artística, es recomendable incluir recursos visuales de creación propia o ajena que aludan de manera clara al contenido presentado en cada una de las pantallas.

Además, es común encontrar algunas WebQuests en Internet que facilitan una guía didáctica, pues resulta muy útil para el resto de profesionales de la educación conocer la base legal que ha servido de referencia para su diseño, los objetivos curriculares a conseguir, las competencias o cualquier detalle que haga de su aplicación en el aula un proceso verdaderamente didáctico.

\subsection{Segunda fase de la experiencia de aula: resultados del diseño de WebQuests con rúbricas de evaluación para Educación Primaria}

En el ámbito de la didáctica, una rúbrica de evaluación la podríamos definir como una guía para valorar el nivel de logro de los estudiantes o de la calidad de todos los aspectos que intervienen en un proceso de enseñanza-aprendizaje (Conde y Pozuelo, 2007; Temprano Sánchez, 2009: 40-42). Debe dar a conocer las características específicas de los diferentes momentos del proyecto didáctico en varios niveles de rendimiento, facilitando unos criterios precisos que permitan el desarrollo de procesos de autoevaluación o coevaluación con carácter objetivo.

Conscientes de que no todas las WebQuests publicadas en la web cumplen unos criterios mínimos de calidad para uso en educación, en la primera fase de este proyecto, tal y como se señalaba párrafos atrás, se llevó a cabo la formulación de una rúbrica que sirviera de referencia a los futuros maestros de Educación Infantil y Primaria para el diseño de WebQuests válidas para cualquier área curricular o etapa educativa. Esta propuesta de trabajo venía a sumarse a la de su propio creador (Dodge, 2001a), que realizó una matriz de evaluación en inglés que ha sido la referencia para otras muchas como la de Francisco Muñoz de la Peña (2013).

En nuestro caso, la rúbrica diseñada por el grupo de investigación se organizó atendiendo a los siguientes elementos básicos (Salido, 2014, 170-172):

- Niveles de calidad: Bajo (0-2 puntos), Medio (2-4 puntos) y Excelente (4-5 puntos)

- Partes de la WebQuest: Introducción, Objetivos, Tarea, Proceso, Recursos, Evaluación y Conclusión. 
- Ítems de calidad: explicación detallada de los criterios utilizados para establecer los diferentes niveles de calidad de cada uno de los apartados que componen la WebQuest.

- Ítems de valoración aplicables a todos los apartados: Ortografía y gramática, Calidad de las imágenes presentadas y Uso ético de la información.

- Puntuación total: el nivel excelente de calidad quedó establecido en un máximo de 50 puntos, lo que supone que por debajo de 25 la WebQuests no reúne unos requisitos mínimos. Si bien, es recomendable que ningún apartado se encuentre en el nivel de calidad bajo.

La principal novedad de esta rúbrica fue incluir ítems de valoración de elementos formales como la ortografía y la gramática o la calidad de las imágenes presentadas, y de un aspecto demasiado importante y en ocasiones olvidado como es el uso ético de la información. En este sentido, se incidió en la necesidad aplicar a las publicaciones web de este tipo las normas de citas y referencias textuales de la American Psychological Association (APA) así como un modelo básico de citas visuales ${ }^{1}$.

Como no podía ser de otra manera, la rúbrica descrita se fundamentó en las Five Rules for Writing a Great WebQuest fijadas por Dodge (2001b):

- $\quad$ Find great sites

- Orchestrate learners and resources

- Challenge your learners to think

- Use the medium

- Scaffold high expectations

Con los resultados de la primera fase como material de referencia, se planteó el segundo momento de esta experiencia de diseño de WebQuests. En este caso, se trabajó con otro grupo de alumnos y alumnas de la asignatura Educación Plástica y Visual, impartida en el Grado de Maestro en Educación Primaria. El objetivo primordial fue que un grupo de investigación ajeno al origen de la rúbrica facilitada valorara de manera crítica las posibilidades que esta ofrecía para el diseño de WebQuests ajustadas a las exigencias curriculares de otros estadios educativos. Es por ello que, a diferencia de la primera fase, en este caso se trabajó en torno al área de Educación Artística de la etapa de Primaria, pues en este momento de la enseñanza reglada resulta fundamental dar a conocer diferentes contenidos histórico-artísticos como complemento a la experimentación plástica propia de esta disciplina.

Los resultados de esta segunda fase evidenciaron, de nuevo, las posibilidades del sistema de evaluación con rúbricas tanto en los procesos de enseñanza-aprendizaje como en el diseño de herramientas didácticas. Desde un primer momento, los estudiantes conocieron el "concepto de WebQuest" y los derroteros que debe seguir su formulación atendiendo a unos criterios de calidad objetivos. Por otra parte, el uso

\footnotetext{
${ }^{1}$ Para las citas de imágenes, en la segunda fase del proyecto se fijaron tres modelos básicos:

I. Imagen de creación propia: Autor, Título, Año. Tipo de imagen.

II. Imagen descargada de Internet: Autor, Título, Año. Tipo de imagen. Recuperado de: http://... [Consulta: fecha].

III. Imagen de obra de arte descargada de Internet: Artista, Título, Año de la obra. Procedencia o autor de la imagen utilizada. Recuperado de: http://... [Consulta: fecha].
} 
de una rúbrica como la utilizada permitió a los fututos profesionales de la educación ser conscientes de que no todas las WebQuests publicadas en Internet son válidas desde el punto de vista didáctico. De ahí la necesidad de adaptar su diseño a los contenidos curriculares de cada disciplina y de aplicar unos criterios de calidad mínimos que eviten que la herramienta diseñada por Dodge y March se convierta en una mera búsqueda y repetición de información virtual que en ocasiones es errónea.

Por otro lado, en esta segunda fase del proceso de investigación volvieron a aparecer opiniones que evidenciaban que la posibilidad de explotar el enfoque construccionista de la WebQuest pasa por el dominio de diferentes capacidades cognitivas, técnicas, actitudinales y éticas (Salido, 2014, 163-164). Si bien, hemos de ser conscientes de que estas competencias no apartan de la palestra de la educación las metodologías de enseñanza-aprendizaje puestas en uso hasta el día de hoy en la enseñanza de las Artes Visuales. Más bien, las aportaciones 2.0 deben servir para aunar tradición y vanguardia didácticamente hablando.

Además, frente a las numerosas ventajas que el uso de la herramienta didáctica de Dodge y March ofrece en el aula de cualquier nivel educativo -fuentes de información de rápida consulta, motivación y participación activa o posibilidades de interacción virtual con otras personas interesadas en el tema-, a lo largo de este proyecto se están evidenciando algunos inconvenientes en torno a los que se hace necesario trabajar para obtener resultados óptimos del uso de la WebQuest en educación. Aparte de la conocida reticencia que muestran algunos docentes a la hora de utilizar herramientas tecnológicas en educación, es destacable que la necesidad de usar Internet en el aula puede llegar a ser una causa de distracción para los alumnos y alumnas. Este aspecto se puede mejorar aportando otras fuentes de información no-virtuales en ese contexto de desarrollo de metodologías que aúnen tradición y vanguardia, o a través de la formulación de tareas que tengan como base para la información inicial Internet pero que su resolución exija apartarse del ordenador. Para el caso del área de Educación Artística, estos aspectos se plantearon en torno al trabajo con recursos de biblioteca, para el primer caso, y planteando tareas de creación y experimentación con distintos materiales y técnicas, para el segundo caso. Este intercambio de fuentes y métodos de trabajo virtuales y no-virtuales permite que el tiempo destinado al uso de Internet se dedique a fines meramente didácticos y de desarrollo de la investigación planteada.

Atendiendo a los criterios expuestos, se diseñaron algunas WebQuest bajo títulos como Descubriendo la obra de Ángel Ferrant, La vanguardia y el arte infantil o iConozcamos la vida y obra de Pablo Picasso! De todas ellas, fue la última la que alcanzó mayor protagonismo entre los integrantes del grupo de investigación por su atractivo proyecto didáctico para trabajar Picasso con los niños. Tras su resolución en el aula y una revisión final de la misma por parte del investigador principal, esta WebQuest ha quedado al servicio de los estudiantes para que pueda ser utilizada en los periodos de Prácticum que incluyen los planes de estudios en Educación (Grupo de Investigación II, 2015) ${ }^{2}$.

\footnotetext{
${ }^{2}$ El informe final y los resultados de cada fase de investigación puede consultarse en el EduBlog Web 2.0 y didáctica de las enseñanzas artísticas <H http://tecnologiayeducacion2012.blogspot.ro/2015/01/nuevas-tecnologias-universidad-y.html H> (Consulta: 30-01-2015).
} 


\section{A MODO DE CONCLUSIÓN}

De un tiempo a esta parte han sido numerosos los estudiosos interesados en vincular tecnología y educación en ese paso de las TIC's (Tecnologías de la Información y la Comunicación) a unas TAC's (Tecnologías del Aprendizaje y del Conocimiento) que buscan orientar las TIC's hacia usos más formativos (Lozano, 2011). En este contexto, es muy común encontrar opiniones que defienden la importancia de fomentar el desarrollo de entornos de aprendizaje 2.0 ante la inminente necesidad de adaptar la práctica docente de cualquier área o etapa de la educación a la realidad de la segunda década del siglo XXI (Gertrudis y Ballesteros, 2014; Araujo, 2014, entre otros). Como es evidente, este hecho exige replantearse la acción pedagógica llevada al aula, así como el papel del docente y de un estudiante que ahora es el protagonista de su proceso de formación.

Como no podía ser de otra manera, la Educación Artística no ha permanecido ajena a este nuevo concepto de enseñanza. Un paseo por la literatura escrita al respecto evidencia que, de un tiempo a esta parte, son numerosas las experiencias desarrolladas en torno a los cambios producidos en el aprendizaje artístico con el uso de blogs, wikis, marcadores sociales o WebQuests (Álvarez, 2007; Saura, 2011; Toro, s. a.). Es por ello que el proyecto que estamos llevando a cabo en la Facultad de Educación de Ciudad Real no viene más que a sumarse a las propuestas de aquellos que día a día trabajan para adaptar esta disciplina a las exigencias de una sociedad que poco a poco avanza hacia el concepto 4.0.

\section{REFERENCIAS}

ADELL SEGURA, J. (2004). Internet en las aulas: las WebQuest. Edutec: Revista electrónica de tecnología educativa, 17. Recuperado de: http://www.cyta.com.ar/presentacion/mejora archivos/edutec.htm (Consulta: 24-01-2015).

ÁlVAREZ, L. (2007). Las TIC's en Plástica. Propuestas de trabajo e ideas TIC para su aplicación en la escuela. [EduBlog]. Recuperado de: http://blog.educastur.es/luciaag/ (Consulta: 22-01-2015).

ARAUJO, J.C. (2014). El uso de blogs, wikis y redes sociales en la enseñanza de lenguas. EDUTEC, Revista Electrónica de Tecnología Educativa, 49. Recuperado de http://edutec.rediris.es/Revelec2/Revelec49/n49 Araujo.html (Consulta: 29-012015).

CARR, W. y KEMMIS, S. (1988). Teoría crítica de la enseñanza: la investigación-acción en la formación del profesorado. Barcelona: Martínez Roca.

CONDE RODRíGUEZ, A. y POZUELO ESTRADA, F. J. (2007). Las plantillas de evaluación (rúbrica) como instrumento para la evaluación. Un estudio de caso en el marco de la reforma de la enseñanza universitaria en el EEES. Investigación en la Escuela, 63, 77-90. http://www.investigacionenlaescuela.es/articulos/63/R63 6.pdf (Consulta: 26-012015). 
DODGE, B. (1995). WebQuests: a technique for Internet-based learning. Distance Educator, 1, 2: 10-13.

---- (2001a). A Rubric for Evaluating WebQuests [Recurso en línea]. Recuperado de http://edweb.sdsu.edu/WebQuest/WebQuestrubric.html (Consulta: 25-01-2015).

---- (2001b). FOCUS: Five rules for writing a great WebQuest. Learning \& Leading with Technology, 28, 8: 6-9, 58. Recuperado de: http://WebQuest.sdsu.edu/focus/focus.pdf (Consulta: 26-01-2015).

ELLIOT, J. (2010). La investigación-acción en educación. (6a ed). Madrid: Morata (1a ed.: 1990).

GÉRTRUDIX, F. y BALLESTEROS, V. (2014). El uso de herramientas 2.0 como recursos innovadores en el aprendizaje de niños y niñas en Educación Infantil. Un estudio de caso de investigación-acción. EDUTEC. Revista electrónica de tecnología educativa.

Recuperado

de:

http://edutec.rediris.es/Revelec2/Revelec49/n49 GertrudixBallesteros.html (Consulta: 28-01-2015).

GRUPO DE INVESTIGACIÓN II (2015). iConozcamos la vida y obra de Pablo Picasso! [WebQuest]. En Pedro (2011). Web 2.0 y didáctica de las enseñanzas artísticas [EduBlog]. Recuperado de: http://tecnologiayeducacion2012.blogspot.ro/2015/01/nuevas-tecnologiasuniversidad-y.html (Consulta: 29-01-2015).

LATORRE, A. (2008). La investigación-acción. Conocer y cambiar la práctica educativa. Barcelona: Graó.

LOMAX, P. (1995). Action research for professional practice. British Journal of InService Education, 21 (19), 49-57. doi: 10.1080/0305763950210105.

LOZANO, R. (2011). De las TIC a las TAC: tecnologías del aprendizaje y del conocimiento. Anuario ThinkEPI, 2011, 5, 45-47. Recuperado de: http://www.thinkepi.net/las-tic-tac-de-las-tecnologias-de-la-informacion-ycomunicacion-a-las-tecnologias-del-aprendizaje-y-delconocimiento\#sthash.Jwnrft2p.dpuf (Consulta: 29-01-2015).

MUÑ̃Z DE LA PEÑA CASTRILLO, F. (2013). Rúbrica para evaluar tu WebQuest [Recurso en línea]. Recuperado de: http://www.aula21.net/tallerwq/fundamentos/mirubrica.htm (Consulta: 25-012015).

PRENSKY, M. (2001). Digital Natives, Digital Immigrants. On the Horizon, 9, (5). October: 1-6. Recuperado de: http://www.marcprensky.com/writing/Prensky\%20\%20Digital\%20Natives,\%20Digital\%20Immigrants\%20-\%20Part1.pdf (Consulta: 2301-2015).

ROIG VILA, R. (2014) (coord.). La WebQuest. Una metodología apoyada en la red para renovar la docencia en Educación Superior. En Ma T. Tortosa Ybáñez, J. D. Álvarez Teruel y N. Pellín Buades (coords.). XII Jornadas de Redes de Investigación en Docencia Universitaria 2014. El reconocimiento docente: innovar e investigar con criterios de calidad. Alicante: Universidad de Alicante, 403-417. Recuperado de: http://rua.ua.es/dspace/bitstream/10045/41781/1/2014 XII Jornadas Redes 32. pdf (Consulta: 24-01-2015).

SALIDO, P.V. (2014). Didáctica de las enseñanzas artísticas impartidas en las Facultades de Educación y Tecnologías de la Información y la Comunicación: la WebQuests 
como estrategia metodológica construccionista. Arte, individuo y Sociedad, 26 (1), 153-172. doi: http://dx.doi.org/10.5209/rev ARIS.2014.v26.n1.41211 SAURA PÉREZ, Á. (2011). Innovación educativa con TIC en Educación Artística Plástica y Visual. Líneas de investigación y estudios de casos. Sevilla: MAD.

TEMPRANO SÁNCHEZ, A. (2009). WebQuest: aproximación práctica al uso de Internet en el aula. Sevilla: Mad.

TORO PRIETO, P. (s. a.). Espiral Cromática y su biblioteca on-line de recursos [EduBlog]. Recuperado de: http://espiralcromatica.wordpress.com/about/ (Consulta: 22-012015).

\section{Para citar este artículo:}

Salido, P. V. (2015). Nuevas tecnologías, universidad y educación artística: el diseño de WebQuest con rúbricas de evaluación en la formación de formadores.. EDUTEC, Revista Electrónica de Tecnología Educativa, 52. Recuperado el dd/mm/aa de http://www.edutec.es/revista. 